\title{
A VONTADE DE VERDADE NO DISCURSO DE CANDIDATURA DO (NÃO)POLÍTICO TRUMP
}

\author{
Eliane Righi de Andrade* \\ Janaina Ferreira Coriolano*
}

\begin{abstract}
RESUM0:0 artigo busca promover uma reflexão sobre a construção dos processos identitários na campanha presidencial do atual presidente dos Estados Unidos, Donald Trump, por meio de representações que circularam na mídia ao longo desse período. Objetiva-se analisar de que maneira essas representações podem ser encontradas nos recortes midiáticos e que efeitos de sentido possíveis são proporcionados. Trabalha-se com o discurso de candidatura de Trump, sob duas perspectivas: a do próprio candidato e da mídia corporativa CNN, a partir de recortes e transcrições de vídeos e reportagens. Trabalhando com a materialidade linguística e imagética dos recortes, analisa-se a construção do discurso da mídia sobre o candidato e suas repercussões na campanha, até 0 acontecimento de sua eleição. Por meio dos recortes, tem-se 0 intuito de compreender de que maneira a "vontade de verdade" trazida por Foucault pode ser encontrada nesse discurso e qual impacto esse recurso trouxe aos eleitores na tomada de decisões. 0 conceito da "vontade de verdade" é, além disso, trazido para dialogar com a "pós-verdade", já que emoções e crenças pessoais parecem, muitas vezes, mais influentes na formação da opinião pública do que fatos. Por meio de análise, foi possível concluir que, embora a mídia desempenhe importante papel na formação das identidades, é impossível controlar os efeitos de sentido que as representações disseminadas produziram, questionando a construção e a existência de uma verdade única e fazendo o imprevisível emergir do acontecimento "eleição americana".
\end{abstract}

PALAVRAS-CHAVE: Discurso da mídia e político; Identidade; Vontade de verdade.

\section{THE WILL TO TRUTH IN THE ELECTION CAMPAIGN OF THE (NON)POLITICAL TRUMP}

\begin{abstract}
The construction of identity processes on the presidential campaign of Donald Trump, the current incumbent of the US presidency, is analyzed through representations released in the media throughout the election period. The manner by which these representations may be found in the media and their possible meaning effects are investigated. Trump's candidate discourses are seen from the candidate's own discourses and from those of the CNN corporation, employing cuttings and transcription of videos and reports. Through the linguistic materiality and imagetics of the cuttings, the construction of the discourse by the media on the candidate is analyzed, coupled to its repercussions in the campaign, up to the results. Cuttings will make us understand Foucault's 'will to truth' in the discourse and their impacts on voters in decision taking. Further, the 'will to truth' communicates with the 'post-truth', since emotions and personal beliefs are frequently more powerful in the formation of public opinion than sheer facts. Results show that, although the media has an important role in identity formation, the meaning effects of disseminated representations produced are difficult to harness, whilst questioning the construction and existence of the sole truth and making the unforeseen emerge from the US election event.
\end{abstract}

KEYWORDS: Media discourse and political discourse; Identity; Will to truth.

\section{INTRODUÇÃO}

0 presente artigo, que se baseia numa perspectiva discursiva da linguagem, estabelece como foco de discussão o papel da mídia na construção de representações sobre o candidato à presidência americana Donald

\footnotetext{
Doutora e pós-doutora em Linguística Aplicada, pela Universidade de Campinas, é professora na graduação (Letras) e no Mestrado interdisciplinar stricto sensu Linguagens, Mídia e Arte, da Pontifícia Universidade Católica de Campinas, Brasil. E-mail: eliane.righi@puc-campinas.edu.br

* Graduanda no curso de Letras e Bolsista pelo CNPq no ano de 2017/2018 de Iniciação Científica no curso de Letras Inglês/Português da PUC/ Campinas, Brasil.
} 
Trump, a partir de seus discursos de campanha nas últimas eleições. Neste trabalho apresenta-se 0 discurso de candidatura de Trump por meio de duas visões: a do próprio candidato (disponibilizado pela C-SPAN) e a de uma plataforma midiática (CNM). A partir dessa contraposição, apresenta-se a "vontade de verdade" como o desejo de que algo seja verdadeiro e, dessa forma, a crença no estabelecimento de uma verdade absoluta. A análise se dá por meio de recortes discursivos que compõem o eixo temático definido como "a vontade de verdade", no qual se discutem os mecanismos utilizados no discurso que norteiam essa "vontade de verdade" e alguns efeitos de sentido que estabelecem com os eleitores.

Discutindo a visão discursiva da linguagem, por um viés da análise francesa do discurso, Gregolin (2006) afirma que esta "é um campo de pesquisa cujo objetivo é compreender a produção social de sentidos, realizada por sujeitos históricos, por meio da materialidade das linguagens" (GREGOLIN, 2006, p. 11). Através desse dispositivo teórico-analítico, é possível compreender os conceitos de formação discursiva, sujeito, discurso, além das condições de produção que norteiam determinado enunciado, a fim de promover uma prática analítica que implica trabalhar a materialidade linguística em sua relação com o contexto histórico social, ou seja, a articulação língua como estrutura e língua como acontecimento.

A partir desta relação, entende-se que a interpretação é um gesto que se faz sobre o material de análise, cuja materialidade se dá em forma de textos verbais e não verbais, ou seja, palavras e imagens que se combinam e produzem efeitos de sentidos, marcados pelas condições de produção do discurso, a partir da posição ideológica em que o sujeito se coloca e, portanto, das formações discursivas das quais participa.

Nessa perspectiva, foi tomado como "acontecimento" discursivo, e como base de análise, um evento muito particular: 0 processo midiático da campanha de Donald Trump para a eleição de 2016. Com base nesse evento, foram selecionados recortes retirados de mídias sociais e corporativas nos mais diversos formatos com 0 objetivo de analisar como diferentes mídias foram construindo representações do candidato republicano Donald Trump até sua eleição como presidente. Para este estudo, foram trazidos dois recortes discursivos: um da reportagem da CNN, que comenta a respeito do discurso de candidatura de Trump proferido no dia 15 de junho de 2015, e outro de um vídeo sobre o mesmo evento, disponibilizado pela C-SPAN, no mesmo dia. Destaca-se que o foco desta pesquisa é o período que antecede a presidência do candidato, mais especificamente o período entre 15 de junho de 2015 até 09 de novembro de 2016, visando 0 estudo da constituição do imaginário na mídia sobre 0 candidato ao longo desse tempo, a qual foi sendo construída e difundida, procurando buscar alguns elementos que permitiram entender sua eleição no contexto social norte-americano e formas de resistência a um olhar da mídia que parecia hegemônico sobre o candidato, de forma que seja possível compreender tal fato como da ordem do imprevisto, uma vez que circulava pelos diferentes veículos a provável eleição da candidata democrata, até poucos dias antes de sua eleição no dia 09 de novembro, de 2016.

0 estudo foi guiado pelo objetivo geral de verificar 0 imbricamento do discurso político com 0 discurso midiático na construção das identidades, a partir de enunciados tomados de diferentes veículos de comunicação americanos sobre a campanha eleitoral de Trump, a fim de compreender se (e como) a mídia pode influenciar a escolha política dos cidadãos e 0 modo de resistir ou aderir aos discursos hegemônicos, refletindo se houve questionamento da construção de uma "verdade" única. Em relação aos objetivos específicos, procurou-se compreender as condições de produção dos dizeres analisados circunscritos a uma realidade histórica e algumas das possíveis representações do candidato Donald Trump que foram delineadas pelo discurso da mídia no período da campanha presidencial.

Entende-se, nessa perspectiva, ainda, que os processos identitários são fluidos e estão sujeitos a fatores da ordem do acaso no campo discursivo, por 
meio da produção de efeitos outros de sentido.

\section{METODOLOGIA E ALGUNS ASPECTOS TEÓRICOS}

Esse estudo foi desenvolvido a partir de uma pesquisa qualitativa interpretativista. A pesquisa qualitativa se insere, enquanto um conjunto de práticas, em um contexto de sua própria multiplicidade de "histórias disciplinares, tensões e contradições constantes em torno do projeto propriamente dito, incluindo seus métodos e as formas que suas descobertas e suas interpretações assumem" (DENZIN; LINCOLN, 2006, p. 21). Optou-se por empregar a análise do discurso de linha francesa como dispositivo analítico, a fim de trabalhar com a materialidade linguística dos recortes na relação com as condições de produção dos enunciados.

Nessa perspectiva, foi feito um levantamento de materiais midiáticos diversos: vídeos, reportagens, imagens, memes, charges, selecionados de mídias sociais também diversas - Youtube, blogs, Twitter - e corporativas - The New York Times, CNN-reunindo um total de 100 recortes coletados, como já mencionado, de junho de 2015 a novembro de 2016 (antes da eleição), que constituíram o corpus inicial da pesquisa. Após essa primeira seleção, foram identificadas certas regularidades discursivas, as quais foram reunidas em três eixos temáticos. Trazemos para este artigo os resultados de análise de dois recortes pertencentes ao eixo designado "vontade de verdade"3.

Este eixo concentra-se no discurso de candidatura de Trump a partir de duas visões: a do próprio candidato e a de uma plataforma midiática. Destaca-se que, neste artigo, foram trazidos dois recortes - um da CNN e outro da C-SPAN - para trabalhar analiticamente a questão da vontade de verdade proposta por Foucault (2002), uma vez que esse dispositivo discursivo aparece nos discursos de candidatura veiculados pelas duas plataformas midiáticas. Antes da análise, porém, faz-se necessário

\footnotetext{
0s outros dois eixos trabalhados foram: "a construção de um (não) político" e "as"minorias no discurso de Trump".
}

compreender alguns conceitos pertencentes ao âmbito dos estudos do discurso, de modo a apresentar uma visão mais clara dos recortes propostos.

Quando se fala em sujeito refere-se ao sujeito discursivo, marcado e formado pela memória discursiva (interdiscurso), na qual estão presentes todos os discursos que foram produzidos ou que seriam possíveis de serem produzidos. Além da memória discursiva, as formações discursivas representam os lugares sociais que o sujeito é "convidado" a assumir. Na visão de Pêcheux (1988, p.160), formação discursiva é "aquilo que, numa formação ideológica dada, isto é, a partir de uma posição dada numa conjuntura dada, [...] determina 0 que pode e deve ser dito". Um sujeito discursivo "participa" de várias formações discursivas, assumindo posições diferentes no interior de cada uma delas, e construindo sua própria memória discursiva, e individual, a partir dos discursos que 0 constituem. Foucault (2002, p. 314) assume uma perspectiva um pouco diferente em relação às formações discursivas, não ligadas apenas às cadeias de regularidade, mas aos sistemas de dispersão, formados a partir de "jogos de diferença, de desvios, de substituição, de transformação". As formações discursivas, dessa maneira, assumem uma natureza dinâmica, podendo gerar sempre a construção de outros efeitos de sentido. Dessa forma, uma formação discursiva não é algo "fechado" na medida em que "é constitutivamente "invadida" por elementos que vêm de outro lugar (isto é, de outras formações discursivas)" (FOUCAULT, 2002, p. 314).

As diferentes posições de sujeito são marcadas pela heterogeneidade dos enunciados e da presença do discurso do outro. Foucault ressalta o discurso do "outro" sendo colocado em prática pelo sujeito e também o discurso do sujeito sendo colocado em prática pelo "outro", ou, ainda, o discurso de um "outro" presente no próprio sujeito, na instância do inconsciente,naqualo "ego-eu,enunciador estratégico coloca em cena 'sua' sequência”. (FOUCAULT, 2002, p. 316). De acordo com Foucault, existem procedimentos internos e externos que controlam e estabelecem a ordem do discurso. 0 sistema de exclusão determina 
quais sujeitos discursivos têm uma posição de poder e, consequentemente, quais sujeitos tem "voz" no interior de determinado discurso.

Pechêux (1997) afirma que "todo enunciado é intrinsecamente suscetível de tornar-se outro, diferente de si mesmo, se deslocar discursivamente de seu sentido para derivar para um outro" (PECHÊUX, 1997, p. 53). Para Gregolin (2006), um enunciado "re-atualiza" outros enunciados (alteridade), retoma discursos outros (interdiscurso) e se torna 0 discurso do outro. Nas palavras de Gregolin "todo discurso é fundamentalmente heterogêneo e está exposto ao equívoco porque se relaciona sempre com um discurso-outro." (GREGOLIN, 2006, p. 32).

Atualmente vive-se numa sociedade midiatizada na qual, na visão de Castells (2006), a mídia se apropria dos meios de informação. Está se diante, pois, da era da informação, um período histórico caracterizado por uma revolução tecnológica concentrada nas tecnologias digitais de informação e comunicação que, além de gerar a eclosão da liberdade, é o momento que as corporações se unem para obter o monopólio da informação. Sgorla (2009) define midiatização como um processo em que as tecnologias midiáticas, técnicas, lógicas, estratégias, linguagens, operações sociotécnicas e demais protocolos das mídias imbricam-se no interior das dinâmicas de funcionamento do tecido social. No universo da midiatização, o sujeito não recebe apenas a informação, mas faz parte dela, a cria, divulga e movimenta, de modo que "a lógica e a cultura midiática passam a orquestrar 0 curso de vida em sociedade, a partir de uma temporalidade, espacialidade, estética e ideologia singular" (SGORLA, 2009, p. 63).

Em relação aos estudos do discurso da mídia, Charaudeau (2006a) afirma que não se deve confundir valor de verdade e efeito de verdade em uma informação. 0 efeito de verdade está no "acreditar ser verdadeiro", diferente do valor de verdade, que se baseia na evidência, e não apenas na convicção, em um saber de opinião. A partir do momento em que a mídia assume uma posição de poder na sociedade, ela torna-se objeto de atenção do mundo político, que precisa dela para sua própria visibilidade. Por meio dos recursos linguísticos, da opção pelo uso de determinada palavra e não outra; dos métodos utilizados para capturar imagens, da seleção daquilo que será ou não transmitido, proporciona-se uma visão fragmentada da realidade, fundamentada sob a ótica de determinada instância midiática, gerando e produzindo diversos efeitos de sentido a respeito de determinado evento. 0 tratamento da informação é a maneira de fazer, o modo pelo qual o sujeito informador decide transpor em linguagem os fatos selecionados, de modo a gerar 0 efeito que escolheu produzir dependendo das escolhas discursivas efetuadas por ele, embora isso seja uma ilusão, pois não há controle total sobre os efeitos de sentido, já que a língua não é transparente.

Woodward (1997) salienta que a identidade é marcada pela diferença, sustentada pela exclusão "eu sou tudo aquilo que o outro não é, e vice-versa" (WOODWARD, 1997, p. 17). É também marcada por meio de símbolos, sendo a construção da identidade tanto simbólica, quanto social. A autora afirma que, no interior dos sistemas de representação, os sujeitos assumem determinadas posições e por meio dos significados produzidos pelas próprias representações é possível dar sentido à experiência e àquilo que se é.

A partir desses conceitos teóricometodológicos, pretende-se empreender a análise dos dois recortes discursivos: um da reportagem veiculada pelo CNN e outro extraído do vídeo do discurso de candidatura de Donald Trump (disponibilizado online pela $C-S P A M$ e discutir alguns efeitos de sentido que deles emergem, com intuito de compreender a construção de representações sobre 0 candidato Donald Trump, além de alguns recursos linguísticos empregados nos discursos de candidatura, como o uso do tempo verbal, o léxico selecionado e a repetição de algumas expressões, de modo a relacioná-los com 0 conceito da "vontade de verdade". 


\section{RESULTADOS DA ANÁLISE}

A seguir é trazida a discussão dos resultados de análise de dois recortes que fazem parte do eixo temático denominado "a vontade de verdade", como explicitado no estudo do método. 0 primeiro recorte foi extraído do site da $C N N^{4}$ da seção de política e trata-se de uma reportagem escrita por Jeremy Diamond, um repórter político, responsável por cobrir reportagens na Casa Branca nos EUA, e, atualmente, sobre a administração de Donald Trump.

A reportagem publicada no dia 17 de junho de 2015 tem como título Donald Trump jumps in: The Donald's latest White House run is officially on ${ }^{5}$, e aborda a confirmação da candidatura de Donald Trump como presidente dos Estados Unidos da América. A reportagem relata o discurso de 45 minutos que Trump realizou em sua campanha, anunciando que concorreria como candidato à presidência, apresentando um vídeo com alguns fragmentos do discurso oficial do candidato e, em seguida, uma reportagem escrita que traz a transcrição de alguns momentos do discurso, bem como as impressões do repórter e da própria $C N N$.

Para a constituição desse recorte, foram selecionados três pequenos trechos do texto escrito pelo repórter Jeremy Diamond.

\section{Recorte 1 \\ "So, ladies and gentlemen, I am officially running for president of the United States, and we are going to make our country great again" [frase dita pelo próprio Trump]. Trump told the crowd in a lengthy and meandering 45-minute speech that hit on his signature issues like currency manipulation from China and job creation, while also taking shots at the president and his competitors on the Republican}

\footnotetext{
A Cable News Network (Rede de notícias a cabo) é um canal de notícias norte-americano fundado em 1980 por Ted Turner e foi o primeiro canal a transmitir uma programação de notícias 24 horas.

5 Donald Trump pula para dentro: a recente candidatura de Donald para a Casa Branca sai oficialmente (tradução nossa).
}

side. [palavras do jornalista Jeremy]. ${ }^{6}$

[...]

"Sadly the American dream is dead," [frase dita pelo próprio Trump] Trump said at the end of his speech [palavras de Jeremy]. "But if I get elected president I will bring it back bigger and better and stronger than ever before." [frase dita pelo próprio Trump]. ${ }^{7}$

[...]

Just over four years after he came closer than ever to launching a campaign before bowing out, Trump made his announcement at the lavish Trump Tower on Fifth Avenue in New York, laying out a vision to match his incoming campaign slogan, "Make America Great Again." [palavras de Jeremy]. ${ }^{8}$ (DIAMOND, 2015.

No primeiro trecho, é possível notar que, após Trump anunciar sua candidatura oficial como presidente dos Estados Unidos, ele diz ao público "and we are going to make our country great again" ${ }^{\text {. Ao }}$ utilizar o pronome our (nosso), é possível inferir que Donald Trump se inclui como parte do país e de certa forma parece se colocar lado a lado com o público, como um cidadão americano comum. Isso também parece sugerido no uso da expressão and we are going to make, que remete ao sentido de que, se 0 candidato se tornasse presidente, ele trabalharia para o bem do país em conjunto com a população, em uma espécie de trabalho colaborativo. Ao se colocar na mesma posição que a população, o candidato parece

\footnotetext{
6 "Então, senhoras e senhores eu estou oficialmente concorrendo para ser presidente dos Estados Unidos e nós tornaremos o nosso país grande novamente". Trump disse à multidão em um longo e sinuoso discurso de 45 minutos que abordou problemas já propostos por sua candidatura como manipulação monetária pela China e oportunidade de trabalho, enquanto também atacava o presidente e seus competidores do lado Republicano (tradução nossa).

7 "Infelizmente o Sonho Americano está morto", disse Trump ao final de seu discurso. "Mas se eu for eleito presidente eu o trarei de volta, maior e melhor e mais forte que jamais visto antes" (tradução nossa).

8 Logo após quatro anos de chegar mais perto do que nunca de lançar uma candidatura antes de pular fora, Trump fez esse anúncio na exuberante Trump Tower na Quinta Avenida em Nova York, expondo uma visão para corresponder ao slogan de sua campanha inicial, "Tornar a América Grande novamente" (tradução nossa).

9 "E nós tornaremos o nosso país grande novamente" (tradução nossa).
} 
apresentar um discurso que 0 aproxima do cidadão, fazendo com que esse último se identifique com ele. A partir do uso do pronome e das expressões, Donald Trump se humaniza, de modo que parece colocarse à disposição da população para mudar 0 país, objetivo que precisa contar com 0 auxílio, no caso, 0 voto, da população - e nessa perspectiva o enunciado sugere que Trump, indiretamente, concede um poder à população, um poder de mudança, de decisão.

É relevante comentar, no que confere à materialidade da linguagem, o uso da expressão make our country great again ${ }^{10}$, uma vez que 0 slogan "Make America great again"11 fez parte da campanha presidencial de Donald Trump em 2016 e estabelece uma relação de interdiscurso, por meio da memória discursiva ${ }^{12}$ que é recuperada de enunciados anteriores. De acordo com reportagens acessadas pelo site da própria CNN, Donald Trump haveria utilizado o slogan durante sua campanha para as primárias do Partido Republicano e depois para a eleição presidencial de $2016 .^{13}$

Destaca-se que Jeremy Diamond descreve 0 discurso de 45 minutos de Donald Trump como lengthy (longo) e meandering (sinuoso). Por "longo" pode-se compreender um discurso extenso e a palavra lengthy em inglês sugere uma conotação um pouco negativa, de algo extenso a ponto de ser "lento" e "cansativo". A palavra meandering, por sua vez, faz referência aos meandros (curvas) de um rio, significando em inglês algo que se movimenta vagarosamente sem uma direção específica e sem um propósito claro. Nessa perspectiva, é possível destacar que Jeremy Diamond apresenta uma visão crítica a respeito do discurso de candidatura de Trump, caracterizando-0 como lento, tedioso, em que o candidato proferiu várias palavras "sem chegar a lugar nenhum".

0 repórter também comenta que durante

\footnotetext{
$\overline{10}$ Tornar nosso país grande novamente (tradução nossa).

11 Tornar a América grande novamente (tradução nossa).

120 slogan haveria se originado durante a campanha de Ronald Regan na eleição presidencial de 1980 com a frase Let's make America great again (Vamos tornar a América grande novamente).

${ }^{13}$ Algumas fontes informaram que Trump tivera essa ideia, em novembro de 2012, logo após a reeleição de Barack Obama, embora houvesse dito, em outra ocasião, que a ideia surgiu em 2014, um ano antes do início de sua campanha.
}

o discurso, Donald Trump abordou problemas já mencionados por sua candidatura e também atacou o presidente da época e seus competidores do lado republicano (While also taking shots at the president and his competitiors on the Republican side). Ao anunciar que os problemas mencionados no discurso eram os mesmos propostos pela candidatura de Trump, sugere-se que não houve a abordagem de nenhum problema e nenhuma proposta nova, parecendo tratar-se de um discurso repetitivo e nada inovador. Focando mais especificamente na expressão taking shots, o termo shootem inglês significa atirar com uma arma de fogo. Dessa forma, a expressão taking shots pode significar dar tiros, atirar, conferindo um sentido metafórico de "atirar", "atacar" por meio de palavras, aleatoriamente. A partir dos gestos interpretativos desses enunciados, na perspectiva da CNN, 0 candidato aproveitou o seu discurso de candidatura, no qual normalmente se abordam as propostas políticas e intenções em caso de eleição, para atacar 0 então presidente Barack Obama, como também oponentes do mesmo partido, visto que Donald Trump foi candidato à presidência do partido Republicano. Nesse instante, cria-se outra representação em torno do candidato, uma representação de um candidato que não possui um "discurso ético", pois precisa atacar seus concorrentes para produzir um discurso convincente e que o público quer ouvir, produzindo, assim, a representação de um candidato "apelativo" e que utiliza a palavra como uma "arma" de poder.

No segundo trecho: Sadly the American dream is dead, Trump said at the end of his speech. But if I get elected president I will bring it back bigger and better and stronger than ever before ${ }^{14}$, nota-se a presença do interdiscurso, ou seja, da memória discursiva que 0 atravessa, por meio do termo American Dream (Sonho Americano) ${ }^{15}$. 0 American

\footnotetext{
14 "Infelizmente o Sonho Americano está morto", disse Trump ao final de seu discurso. "Mas se eu for eleito presidente eu o trarei de volta, maior e melhor e mais forte que jamais visto antes" (tradução nossa).

15 Uma ideia popular norte-americana enraizada na Declaração da Independência dos Estados Unidos, na qual aparecem os dizeres de que "todos os homens são iguais" e com direito a "vida, liberdade, propriedade e a busca pela felicidade".
} 
Dream $^{16}$ se estabelece pela crença de que todos nos Estados Unidos têm a chance para o sucesso e para a felicidade, maior mobilidade social para as famílias e crianças, alcançada pelo trabalho duro em uma sociedade sem obstáculos.

Baseando-se na transcrição do fragmento do discurso do candidato, disponibilizado na matéria de Jeremy Diamond, pode-se dizer que Donald Trump afirma que as pessoas deixaram de acreditar no "Sonho Americano" ("Infelizmente o Sonho Americano está morto"). Ao dizer que o sonho encontra-se "morto", pode-se compreender que não há mais ninguém para alimentá-lo, que acredite nele para que possa continuar existindo. Além disso, o candidato ressalta em seu discurso que ele tem a capacidade para trazer o "Sonho Americano" de volta, de uma maneira jamais vista antes. A partir dessa constatação, podese ressaltar que 0 candidato acredita que apenas ele tem a capacidade de fazer com que as pessoas voltem a acreditar no "Sonho Americano" de uma maneira extremamente forte. Além disso, a expressão but if I get elected president I will [...] evidencia 0 uso do primeiro condicional (first conditional) em inglês, que marca algo que ainda tem a possibilidade de se realizar, podendo fazer referência ao fato de Trump tornar-se presidente.

No último trecho selecionado ${ }^{17}$, a $C N N$ destaca que o discurso de Donald Trump foi proferido na Trump Tower, localizada em um local nobre da cidade de Nova lorque (Fifth Avenue) ${ }^{18}$, através da expressão lavish (exuberante) - que significa algo abundante em quantidade, caro e que causa grande impressão - , podendo remeter à representação de Donald Trump como um sujeito rico, de muitas posses

\footnotetext{
${ }_{16} 0$ historiador James Truslow Adams (1931), ao definir o "Sonho Americano", afirmou que "a vida deveria ser melhor e mais rica e mais completa para todos, com oportunidades para todos baseado em suas habilidades ou conquistas, independente de sua classe social ou circunstâncias do nascimento." (CAMBRIDGE DICTIONARY 2018).

17 Retomamos a tradução do trecho: Logo após quatro anos de chegar mais perto do que nunca de lançar uma candidatura antes de pular fora, Trump fez esse anúncio na exuberante Trump Tower na Quinta Avenida em Nova York, expondo uma visão para corresponder ao slogan de sua campanha inicial, "Tornar a América Grande novamente" (tradução nossa).

${ }_{18}$ Uma das ruas mais famosas e caras do mundo, a Quinta Avenida é um símbolo de riqueza e ostentação do discurso capitalista que Trump representa. (WIKIPEDIA, 2018)
}

e estabelecendo uma referência interdiscursiva com a sua faceta empresarial, de businessman (homem de negócios).

A expressão Just over four years after he came closer than ever to launching a campaign before bowing out ${ }^{19}$ pode se referir também ao fato de Donald Trump ter tentado receber a nomeação presidencial anteriormente pelo partido Reformista e ter se retirado antes da convenção. A expressão closer than ever (mais perto do que nunca) sugere que Donald Trump havia chegado muito perto de lançar uma campanha, antes de se candidatar oficialmente como presidente dos Estados Unidos, mas havia "pulado fora", expressão que remete ao fato de alguém deixar de fazer parte de uma situação, de maneira rápida e repentina. Nessa perspectiva, a candidatura de Trump, em 2015, corresponderia à sua primeira candidatura oficial e, consequentemente, o mais próximo que haveria chegado ao campo político.

No último trecho ${ }^{20}$ selecionado, 0 repórter comenta que o discurso de Donald Trump havia sido elaborado de forma que correspondesse ao slogan de sua campanha inicial "Tornar a América grande novamente". A expressão Lay Out, em inglês, significa a maneira como algo é organizado, ou "arranjado". Dessa forma, pode-se comentar que 0 discurso de Donald Trump foi organizado fazendo uma articulação com o slogan de sua campanha, ou seja, a afirmação sugere que os tópicos que o discurso abordou faziam referência ao fato de 0 candidato ter a capacidade de "Tornar a América grande novamente". Além disso, a expressão Lay Out pode indicar que o discurso foi arquitetado, pensado e elaborado anteriormente com 0 propósito de convencer o público de que Donald Trump poderia melhorar a situação do país, o que contradiz um pouco a própria posição do jornal, que caracterizou o discurso do candidato como "sinuoso" e sem um propósito claro e específico (mas ele procura informar com sua aparente "objetividade" uma "verdade"). A palavra great, presente no slogan Make America

\footnotetext{
${ }_{19}$ Logo após quatro anos de chegar mais perto do que nunca de lançar uma candidatura antes de pular fora (tradução nossa).

${ }^{20}$ [...] laying out a vision to match his incoming campaign slogan, "Make America Great Again."
} 
Great Again, pode remeter ao sentido de extenso, mas também de algo "ótimo", "incrível". Pode-se ainda comentar que "grande" em um de seus sentidos metafóricos parece fazer referência ao país como uma potência, que se encontra "na frente" dos outros países em razão de seu progresso, desenvolvimento econômico, tecnologia e demais áreas. Assim, Donald Trump, ao dizer que faria os "Estados Unidos grande novamente", procura enfatizar que tornaria o país uma potência, o "primeiro" do mundo, como foi reconhecido durante muito tempo.

A partir da análise dos trechos em conjunto, pode-se fazer algumas considerações gerais a respeito da reportagem da CNN. Nesse recorte, como um todo, abordam-se duas instâncias de poder, o discurso midiático e o discurso político. De acordo com Foucault (2002), há discursos de poder na sociedade e dentro de uma maquinaria discursiva existem determinadas posições, aqueles que "têm voz" e aqueles que "não têm". 0 "ter voz" interfere de forma acentuada no valor de verdade que determinado discurso terá dentro de uma sociedade. Nessa instância, o discurso da mídia é muito atuante dentro de uma sociedade, exercendo poder e sendo facilmente tomado como "verdade", assim como o discurso político. Ambos são poucas vezes questionados e avaliados quanto a sua veracidade. Na reportagem, é possível notar a contraposição do discurso político proferido por Donald Trump e o discurso da mídia, ou seja, os "fatos" são colocados em contraponto por aquele que os conta.

Da mesma forma, o discurso político faz uso do poder da palavra para convencer, persuadir. No discurso de Donald Trump, transcrito pelo repórter Jeremy Diamond, o candidato faz menção a elementos, como o slogan Make America Great Again (Tornar a América grande novamente) e The American Dream (0 Sonho Americano) que condizem com o que pode ser denominado de "identidade americana", a maneira com que muitos habitantes dos Estados Unidos se veem, pensam e acreditam. Comenta-se que, ao trazer a "identidade americana", o candidato aproxima-se do público e dessa forma provoca uma identificação dos eleitores não apenas com suas propostas, mas com sua própria figura.

Pode-se ainda relacionar 0 enunciado ao conceito de "vontade de verdade" trazido por Foucault (2002). Primeiramente é importante dizer que a "vontade de verdade" não se iguala à definição do discurso de verdade. 0 primeiro conceito opera pelo "consenso da verdade" e quando um sujeito ocupa uma posição de poder no interior de um espaço discursivo e coloca seu discurso em uma posição de verdade absoluta, na qual se deseja acreditar, há uma "vontade de verdade" colocada em prática (FOUCAULT, 2002, p.17). Ao fazer afirmações como But if I get elected president I will bring it back bigger and better and stronger than ever before ${ }^{21}$ e Sadly The American Dream is dead², o candidato parece propor um discurso que acredita ser verdadeiro, um discurso que não precisa de questionamento, basta aos eleitores acreditarem. Pelos recursos linguísticos e pelo fenômeno da "vontade de verdade", Donald Trump apresenta uma tentativa de tornar seu discurso uma verdade e, dessa forma, convencer os eleitores a votarem nele.

0 conceito da "vontade de verdade" pode dialogar com o conceito da "pós-verdade", uma vez que as emoções e crenças pessoais se assumem como mais influentes na informação pública do que fatos objetivos. De acordo com Santos e Spinelli (2017), a "pós-verdade" surge no momento em que as pessoas começam a evitar verdades desconfortáveis. No universo da "pós-verdade", rumores, fofocas e mentiras se espalham com maior velocidade em um cenário formado em redes cujos integrantes confiam mais uns nos outros do que em qualquer órgão tradicional da imprensa. (2017, p.2). 0 universo da "pós-verdade" proporciona 0 desencadeamento de fenômenos como as Fake News, que podem ser definidas como notícias que são "intencionalmente e comprovadamente falsas". De acordo com os autores, 0 próprio Trump haveria ajudado a fixar 0 termo Fake News em uma associação perigosa com

\footnotetext{
${ }_{21}$ Mas se eu for eleito presidente eu o trarei de volta, maior e melhor e mais forte que jamais visto antes (tradução nossa).

22 Infelizmente 0 Sonho Americano está morto (tradução nossa).
} 
veículos reconhecidos pela credibilidade, como a CNN, "em uma guerra nunca antes vista contra a grande imprensa" (AHRENS, 2017; IANDOLI, 2017 apud SANTOS; SPINELLI, 2017, p. 4).

No mundo midiatizado a questão da "verdade" torna-se ainda mais relativizada, uma vez que 0 excesso de informação transborda os limites daquilo que é "real" e daquilo que se "quer fazer acreditar". Como afirma Charaudeau (2006), as mídias não transmitem aquilo que ocorre na realidade social, mas constroem uma representação dessa realidade por meio de sistemas simbólicos que são compartilhados. A linguagem é um desses sistemas e não é, como qualquer sistema de representação, transparente. Essa representação está condicionada pelas relações de poder na sociedade e por fatores internos ao discurso midiático, que obedece também a um conjunto de regras próprias à sua ordem discursiva.

Santos e Spinelli (2017), ao comentar as considerações de Manjoo (2008) em relação à mente humana, descrevem uma das teorias da organização do pensamento que se filia à escolha de informações atreladas às crenças, atitudes e comportamentos humanos, teoria que explica a rejeição do que é contraditório. Essa ideia pode apresentar-se como uma explicação do crescimento da pós-verdade, ou seja, da crença nessa "verdade" que é atrativa aos interesses, anseios e sentimentos.

Em relação às condições de produção do segundo recorte que se apresenta a seguir, trata-se de excerto transcrito de um vídeo veiculado no canal do YouTube ${ }^{23}$ pela $C-S P A N$, no dia 16 de junho de 2015. 0 vídeo corresponde ao discurso de 45 minutos de Donald Trump, realizado na Trump Tower, em que 0 candidato anuncia sua candidatura oficial para a presidência dos Estados Unidos.

A C-SPAN (Cable-Satellite Public Affairs Network ${ }^{24}$ é uma rede de televisão a cabo nos Estados Unidos, criada em 1979 pela indústria de televisão a

\footnotetext{
${ }^{23} 0$ YouTube é uma plataforma de compartilhamento de vídeos em que se é possível acessar vídeos de temas e gêneros variados, como clipes musicais, notícias, tutoriais e até filmes.

${ }^{24}$ Rede de Assuntos Públicos via Satélite-Cabo (tradução nossa).
}

cabo como forma de um serviço público. ${ }^{25} \mathrm{Na}$ descrição, elaborada pela rede $C-S P A N$, que acompanha o vídeo, têm-se os dizeres: "Donald Trump announced his bid for the Republican presidential nomination. He made the announcement at Trump Tower in New York City". ${ }^{26}$

Para compor esse recorte, foram selecionados três trechos do vídeo do discurso de candidatura de Donald Trump e realizada, então, a transcrição da materialidade linguística:

\section{Recorte 2}

"When did we beat Mexico at the border, they are laughing at us, at our stupidity and now they are beating us economically, they are not your friend, believe me" $3: 11 \mathrm{~min}^{27}$

$[\ldots]$

"When Mexico sends its people they are not sending their best, they are not sending you, they are not sending you. They are sending people that have lots of problems, and they are bringing those problems with us. They are bringing drugs, they are bringing crime, they are rapists. And some I assume are good people, but I speak to border guards and they tell us what we are getting". $-3: 40 \min ^{28}$

[...]

"You don't hear it from anybody else, you don't hear it from anybody else" 11:20min ${ }^{29}$ (C-SPAN, 2015).

\footnotetext{
${ }^{25}$ A rede é responsável por televisionar muitos processos do governo federal dos Estados Unidos, como também programas de assuntos públicos. A C-SPAN conta com três canais de televisão, uma estação de rádio e um grupo de websites que oferecem transmissão online $\mathrm{e}$ arquivos de programas da $C$-SPAN (WIKIPEDIA, 2018).

${ }^{26}$ Donald Trump anunciou sua concorrência à nomeação da candidatura presidencial Republicana. Ele realizou o anúncio na Torre Trump na cidade de Nova lorque (tradução nossa).

${ }^{27}$ Quando nós combatemos 0 México na fronteira, eles estão rindo de nós, de nossa estupidez e agora eles estão nos vencendo economicamente, eles não são seus amigos, acredite em mim (tradução nossa).

${ }^{28}$ Quando o México envia seu povo eles não estão enviando o melhor deles, eles não estão enviando vocês, eles não estão enviando vocês. Eles estão enviando pessoas que têm muitos problemas e eles estão trazendo esses problemas para nós. Eles estão trazendo drogas, eles estão trazendo crimes, eles são estupradores. Algum deles eu assumo que são boas pessoas, mas eu converso com os guardas de fronteira e eles nos dizem o que estamos recebendo (tradução nossa).

${ }^{29}$ Vocês não escutam isso de mais ninguém, vocês não escutam isso de mais ninguém (tradução nossa).
} 
No recorte, 0 enunciador apresenta-se como um sujeito discursivo que ocupa uma posição de poder dentro da formação discursiva que representa, ou seja, ele assume dentro do discurso político essa ordem hegemônica. Pode-se salientar que Donald Trump, no momento do discurso de candidatura, coloca-se como um político e representante do partido Republicano, podendo tornar-se futuro presidente e, dessa forma, apresenta uma posição de poder.

Observando o primeiro trecho do recorte, é possível notar a predominância do tempo verbal presente do indicativo, em sua forma progressiva they are laughing at us, at our stupidity and now they are beating us economically $y^{30}$, marcando uma afirmação. É relevante comentar também que 0 presente do indicativo na forma progressiva, em inglês, é geralmente utilizado para se referir a ações que estão acontecendo, ou serão realizadas com certeza, como planos. Ao utilizar tal tempo e aspecto verbal, o candidato parece afirmar essas constatações com veemência, reafirmando a "vontade de verdade". Nota-se, ainda, que Donald Trump não declara dados que comprovem que 0 "México apresenta determinada postura em relação aos Estados Unidos", numa tentativa de construir uma verdade sem a necessidade de comprovação ou questionamento. Nota-se também o uso do pronome pessoal "nós" (us) e possessivo "nosso" (our) e, ao optar pelo uso desses pronomes, 0 candidato parece se incluir nos problemas que se apresentam no país e aproximar-se da população, colocando-se na posição de um cidadão "comum" e parecendo estabelecer uma relação de humanização e identificação para com ele.

0 primeiro trecho estabelece uma relação com 0 "já-dito", pertencente à memória discursiva, ao abordar tema já recorrente em seus dizeres: primeiramente referente ao México, visto que Donald Trump é conhecido pelas declarações divulgadas em plataformas midiáticas sobre "combater" a entrada de imigrantes no país via fronteira mexicana. É relevante comentar que há intenso fluxo de estrangeiros (não

\footnotetext{
30 Eles estão rindo de nós, de nossa estupidez e agora eles estão nos combatendo economicamente (tradução nossa).
}

só mexicanos) na tentativa de ingressar aos Estados Unidos clandestinamente pelo México. Outra relação com 0 interdiscurso, que é constituído pela memória discursiva, pode ser levantada a partir da expressão And now they are beating us economically ${ }^{31}$, que sugere uma referência à necessidade de tornar o país o "maior" e o "melhor", difundindo um pensamento prevalecente na identidade americana de que os Estados Unidos são e necessitam ser sempre a maior e primeira potência mundial, o que indica um imaginário de ser melhor que os demais países, trazendo à memória a própria história de colonização americana, por meio da formação religiosa protestante.

Ao usar a expressão they are not your friend, believe $m e^{32}$, 0 candidato afirma que os mexicanos não são amigos das pessoas que fazem parte do público que escuta 0 discurso. Ao fazer essa afirmação, 0 candidato não apresenta dados concretos, apenas diz believe me (acredite em mim). A expressão muito utilizada e repetida ao longo do discurso e, em outros discursos proferidos pelo candidato, revela uma "vontade de verdade", de maneira que o candidato parece se colocar como detentor da verdade, portador da verdade absoluta, na qual ele mesmo é a própria verdade e quer que os eleitores pensem da mesma maneira.

0 pronome possessivo your (They are not your friend) no inglês pode relacionar-se tanto ao singular quanto ao plural, podendo fazer referência ao "seu amigo" ou "amigos de vocês". Nessa perspectiva, pode-se comentar que Donald Trump, por meio de seu discurso, tem o objetivo de atingir os eleitores como um grupo, mas também de forma individual. Ao atingir os eleitores de forma individual, seu dizer revela a preocupação com cada cidadão, o que pode acabar gerando uma sensação de "falsa" proximidade, como se cada eleitor se sentisse parte da vida do candidato. No segundo trecho, o candidato afirma que When Mexico sends its people they are not sending their best, they are not sending you, they are not

\footnotetext{
${ }_{31}$ E agora eles estão nos superando economicamente (tradução nossa).

${ }^{32}$ Eles não são seus amigos, acredite em mim (tradução nossa).
} 
sending you ${ }^{33}$. Nota-se mais uma vez a "vontade de verdade" que se instala a partir de afirmações feitas pelo candidato, ao dizer que o México não envia as "melhores pessoas" para os Estados Unidos. 0 dizer de Donald Trump sugere que os mexicanos apresentam muitos problemas para 0 país (como drogas, crime e casos de estupro). A afirmação they are not sending you (eles não estão enviando você(s)) pode apresentar-se como uma tentativa discursiva de valorizar o eleitor presente no evento e fazer com que o próprio eleitor estrangeiro se enxergue dessa forma, parte daquela nação. Essa expressão pode trazer como efeito de sentido a questão de que os mexicanos não estão enviando 0 melhor deles e não estão enviando aqueles a quem Trump se dirige (os sujeitos presentes no momento de seu discurso de candidatura), que seriam pessoas "boas".

Ao citar os "problemas" que os mexicanos levam para os Estados Unidos, 0 candidato transfere certa responsabilidade - ou grande parte dela - dos problemas que se apresentam no país não apenas para os mexicanos, mas para os imigrantes como um todo. Utilizando a palavra "México" e fazendo referência ao país, Donald Trump pode se referir a ele unicamente, como também pode estar utilizando uma metonímia (a parte pelo todo) em que o México representaria todas as nações "estrangeiras".

A partir dessa leitura, sugere-se que 0 candidato explica que, sem a entrada de imigrantes, 0 país poderá se tornar melhor, com menos problemas, crimes, drogas e estupros, estabelecendo uma espécie de discurso subentendido nas relações de Donald Trump com as minorias imigrantes. Uma relação com a memória discursiva que se estabelece no segundo recorte é por meio do slogan America for Americans (América para os americanos), um princípio da doutrina estabelecida em 1823 pelo presidente James Monroe $^{34}$. Entre outros princípios, essa doutrina defendia que nenhuma nação americana poderia

\footnotetext{
${ }^{3}$ Quando o México envia o seu povo, eles não estão enviando o melhor deles, eles não estão enviando você, eles não estão enviando você (tradução nossa).

${ }^{34}$ A denominada Doutrina Monroe, pretendia postar a posição dos EUA enquanto liderança continental capaz de garantir a soberania das nações latino-americanas frente às potências europeias.
}

ser recolonizada ${ }^{35}$. A abordagem que 0 candidato apresenta a respeito dos mexicanos generaliza alguns conceitos "eles estão trazendo drogas, eles estão trazendo crime, eles são estupradores”, principalmente pelo uso do tempo verbal presente do indicativo, que se caracteriza principalmente por descrever fatos, afirmações, e do aspecto progressivo, que é muito importante para indicar ações que estão acontecendo no momento. Apesar desse teor de generalização que se apresenta no discurso do candidato, ele acentua que se refere aos mexicanos que entram nos Estados Unidos ilegalmente, e não a todos os mexicanos. Donald Trump ainda comenta and some I assume are good people ${ }^{36}$, dessa forma parecendo esclarecer que alguns mexicanos são pessoas boas, mas que muitos não são e acarretam problemas para o país.

Algo relevante a ser comentado é que o termo assume no inglês significa supor algo, sem 0 uso de dados ou provas, ou seja, algo que não se pode ter certeza absoluta. A partir do uso do termo em "eu assumo que sejam boas pessoas", o candidato afirma que não se pode ter certeza de que os mexicanos que estão sendo citados são pessoas boas, pois, a partir de seu discurso, não estabelece esse conceito como uma verdade absoluta, como faz em outros momentos, ou seja, deixa transparecer certo preconceito em relação aos estrangeiros.

Ao longo de seu discurso, 0 candidato apresenta muitas repetições, como é possível observar na terceira parte do recorte: You don'thear it from anybody else, you don't hear it from anybody else (Vocês não escutam de mais ninguém, vocês não escutam de mais ninguém), assim como as expressões It's true (é verdade), think of it (pense sobre isso). Esses recursos linguísticos, assim como a escolha dos tempos verbais (além de outros recursos paralinguísticos que aqui não foram levantados por trabalhar-se com a transcrição), não se apresentam ao acaso e se referem, possivelmente, a uma tentativa de persuasão do candidato, de forma que os eleitores possam acreditar nele, confiar nele e,

\footnotetext{
35 Além disso, pautava a autonomia econômica dessas mesmas nações, assinalando que a Europa não poderia interferir nos negócios estabelecidos pelas nações da América.

${ }^{36}$ E alguns eu assumo que sejam boas pessoas (tradução nossa).
} 
consequentemente, votar nele. Ao dizer You don't hear it from anybody else, you don't hear it from anybody $e l s e^{37}$, após fornecer algumas informações para os ouvintes, o candidato coloca-se em uma posição de "amizade" com a população, como aquele que expõe as verdades, que não esconde nada do público, diferente dos demais políticos.

Durante 0 vídeo é possível notar que a Trump Tower está com a presença de muitas pessoas, fotógrafos e membros da imprensa e, em vários momentos, o público se manifesta por meio de "gritos", aplausos e frases como "é isso aí", "eu te amo" e outras expressões de simpatia e apoio. Nesse ponto é possível comentar que, por essas reações, há pessoas que apoiam e concordam com os dizeres do candidato, dessa forma identificando-se com ele.

Por fim, salienta-se que o discurso proferido por Trump pôde ocasionar muitos efeitos e produções de sentido e uma das representações possíveis, delineada pelo próprio candidato em seus dizeres, é a de um sujeito que se apresenta como um cidadão, que preza pelos interesses da população e pretende preservá-los ao longo de seu possível mandato. Além disso, apresenta-se como um candidato que é capaz, tem o poder de mudar a situação do país e trazer 0 que a população deseja, um "político" que não age como político, mas como um membro da população, porém bem informado e detentor da verdade, capaz de resolver seus problemas, como se ele fosse um "salvador" da pátria.

\section{ALGUMAS CONCLUSÕES}

Um dos objetivos principais propostos era 0 de estudar quais as possíveis representações que foram construídas em torno de Donald Trump em seu período de candidatura. Identificou-se, dessa forma, que a mídia foi responsável por disseminar, por meio da repercussão de efeitos variados de sentido, muitas representações a respeito desse

\footnotetext{
37 Vocês não escutam de mais ninguém, vocês não escutam de mais ninguém (tradução nossa).
}

sujeito do discurso, como a representação de um "não político", um sujeito despreparado para ocupar o cargo, a representação de um candidato que não é gentil e não apresenta um bom caráter, dentre outras representações possíveis. Deve-se enfatizar, porém, que construir representações a respeito de um sujeito no discurso, não significa ter o controle dos efeitos e produções de sentido que elas podem ocasionar. Por mais que a mídia construa determinada imagem do candidato e se coloque em uma posição de poder para disseminá-la, não há garantia de que 0 expectador/ eleitor assuma a mesma perspectiva ideológica que determinada plataforma pretende transmitir.

Outra questão que se deve considerar é que os sujeitos são formados por diferentes formações discursivas e, a partir disso, estabelecem crenças, ideologias e constituem determinada identidade singularmente. Nessa perspectiva, ter, talvez, a "intenção" de produzir um determinado efeito de sentido, pelo fato de a mídia também representar certas formações discursivas dominantes, não significa que o sujeito-eleitor irá interpretar algo da mesma forma ou se identificar com a mesma ideia, assim como outro sujeito pode conferir um efeito de sentido completamente diferente, segundo suas formações. Nesse ponto, tem-se de concordar com 0 fato de que os sentidos derivam, não podem ser controlados, por mais que se deseje ter 0 controle sobre suas interpretações, e seus efeitos podem ser tanto devastadores quanto possibilitarem formas de resistência a um pensamento único (seja ele da mídia, seja ele de um candidato representante de um partido político).

Foi possível compreender também a maneira que as representações atuam na construção de identidades. Muitas vezes, como no caso da CNN, as plataformas midiáticas colocaram Donald Trump como um sujeito que não se encaixava na posição de presidente e como alguém que apresentava um discurso por vezes "absurdo" e de quem demonstrava despreparo. No entanto, apesar dessa "imagem", muitos eleitores apresentavam os mesmos pensamentos e ideias que 0 candidato, visto que ele 
exibia um discurso muito condizente com a identidade americana mais conservadora, discurso esse que se sustenta no argumento de manter os Estados Unidos como a grande potência mundial, alimentado pelo "sonho americano", o que fez com que muitos eleitores se identificassem com seus dizeres.

A partir da análise dos recortes, foi possível perceber que a mídia se instala em uma posição de poder por disseminar fatos e deles trazer uma perspectiva, consequentemente, constituindo um discurso que deseja também ser de verdade na sociedade. Por meio dessa posição de poder, muitos discursos são, muitas vezes, assumidos como verdade no interior das formações discursivas, sendo poucas vezes questionado. Por outro lado, 0 dispositivo de "vontade de verdade", presente no discurso de candidatura de Trump, teve como intuito colocar o discurso do candidato em uma posição de verdade absoluta e pode ter contribuído para que alguns eleitores 0 concebessem como 0 "detentor da verdade", o sujeito responsável por "levar a verdade" para a população e, nessa perspectiva, identificar-se com ele.

\section{REFERÊNCIAS}

AHRENS, J. M. Trump e as 'fake news' atacam de novo. El Pais, Washington, 08 maio 2017. Disponível em: <https://goo.gl/Jqdx3B> Acesso em: 24 jul. 2017.

CASTELLS, M. 0 poder da identidade. SP: Paz e Terra, 2006.

CHARAUDEAU, P. Discurso das mídias. SP: Ed. Contexto, 2006a.

CHARAUDEAU, P. Discurso político. SP: Ed. Contexto, 2006b.

C-SPAN online. Donald Trump Presidential Campaign Announcement Full Speech. 15 jun 2015. Disponível em: <www.youtube.com/watch?v=apjNfkysjbM\&$t=539$ s $>$. Acesso em: 31 jul 2017.

DENZIN, N. K.; LINCOLN, Y.S. 0 planejamento da pesquisa qualitativa: teorias e abordagens. Porto
Alegre: Bookman/Armed, 2006.

DIAMOND, J. Donald Trump jumps in: The Donald's latest White House run is officially on. CNN online. 17 jun 2015. Disponível em: <https://edition.cnn. com/2015/06/16/politics/donald-trump-2016-announcement-elections/index.html >. Acesso em: 10 mar 2018

FOUCAULT, M. A ordem do discurso. 8. ed. São Paulo: Loyola, 2002.

GREGOLIN, M. R. AD: descrever-interpretar acontecimentos cuja materialidade funde linguagem $e$ história. In NAVARRO, P. (Org.). Estudos do texto e do discurso: mapeando conceitos e métodos. São Carlos: Claraluz, 2006.

GREGOLIN, M. R. Análise do discurso e mídia: a(re) produção de identidades. Comunicação, mídia e consumo, SP, v. 4, n. 11, p. 11-25, nov, 2007.

IANDOLI, R. Trump, 'fake news' e a guerra declarada contra a imprensa. Nexo, 03 jul. 2017. Disponível em: <https://goo.gl/sw7Wvq>. Acesso em: 10 jul. 2017.

MANJO0, F. True Enough: learning to live in a post-fat society. John Wiley \& Sons: New Jersey, 2008.

PÊCHEUX, M. Semântica e discurso. Campinas: Editora da Unicamp, 1988.

SGORLA, F. Discutindo o "processo de midiatização". Revista Mediação, Universidade FUMEC, v. 9, n. 8, jan./jun. 2009.

SPINELLI, E.; SANTOS, J. Pós-verdade, fake News e fact-checking: impactos e oportunidades para 0 jornalismo. In: ENCONTRO NACIONAL DE PESQUISADORES EM JORNALISMO, 15., 2017, ECA/ USP, São Paulo. Anais... SBP Jor - Associação Brasileira de Pesquisadores em Jornalismo, nov. 2017.

WOODWARD, K. Identidade e diferença: uma introdução teórica e conceitual. In: SILVA, T.T. da (Org.). Identidade e diferença: a perspectiva dos estudos culturais. Petrópolis: Vozes, 2000.

Recebido em: 30/09/2018

Aceito em: 19/11/2018 